\title{
Isolation and identification of Marek's disease virus (MDV) from feather follicle epithelium and internal organs of diseased chickens in Dakahlia Governorate, Egypt
}

\author{
El-Kenawy, A. A. ${ }^{1}$, Emad, A. ${ }^{1}$ and El-Tholoth, M. ${ }^{1}$ \\ ${ }^{1}$ Department of Virology, Faculty of Veterinary Medicine, Mansoura University, Mansoura, Egypt
}

\section{ABSTRACT}

\begin{abstract}
In the present study, a total of 16 samples including feather follicle epithelium, ovary, spleen and kidney (4 samples for each organ) were collected from diseased chicken flocks suspected to be infected with Marek's disease virus (MDV) at Dakahlia Governorate, Egypt during the period from October 2016 to October 2017. Each sample was pooled randomly from three to five birds ( 90 to 360 days old). The isolation of the suspected virus from the collected samples was carried out via chorioallantoic membranes (CAMs) of 12 days old embryonated chicken eggs (ECEs). Three egg passages were carried out for each sample. Hyperimmune serum was prepared against standard MDV. MDV in both field and egg passaged samples (after $3^{\text {rd }}$ passage) was identified by agar gel precipitation test (AGPT) and indirect fluorescence antibody test (IFAT). Molecular identification of virus was carried out by conventional polymerase chain reaction (PCR) and real- time PCR in four selected samples. The results revealed that 14 samples $(87.5 \%)$ including $4(100 \%)$ samples from feather follicle epithelium, ovary and kidney and 2 (50\%) samples from spleen, showed positive results in virus isolation after $3^{\text {rd }}$ passage. The positive results percentage by AGPT for field samples were $50 \%$ (8 out of 16 samples), while after the $3^{\text {rd }}$ passage in ECEs were $37.5 \%$ ( 6 out of 16 samples) and the positive results percentage by IFAT for field samples were $62.5 \%$ (10 out of 16 samples), while after the $3^{\text {rd }}$ passage in ECEs were $81.25 \%$ (13 out of 16 samples). Viral nucleic acid was detected in all selected samples by conventional and real- time PCR. The results indicate that feather follicle epithelium is the best organ for MDV detection. IFAT is superior over AGPT in virus detection. Conventional and real - time PCR could be efficiently used for molecular detection of the virus.
\end{abstract}

Keywords: Marek's disease virus, Virus isolation, Agar gel precipitation test, indirect fluorescence antibody test, conventional and real-time (PCR).

\section{INTRODUCTION}

Chicken neoplastic disease is attributed to three groups of viruses: Marek's disease virus, reticuloendotheliosis virus and avian leukosis virus (McKay, 1998). One of the highly contagious diseases is the Marek's disease (MD) which is a lymphoproliferative disease occuring worldwide. MD is characterized by immunosuppression, polyneuritis and T cell lymphomas in susceptible birds. Marek's disease virus (MDV) is the causative agent that is an oncogenic avian herpesvirus (Witter and Schat, 2003).

MDV belongs to family Herpesviridae, subfamily Alphaherpesvirinae, genus Mardivirus and species: Gallid herpesvirus 2, Gallid herpesvirus 3 and Meleagrid herpesvirus 1 (Davison, 2010). These species of MDV group are classified under three serotypes $-1,2$ and 3 on the basis of their patghogenicity and virulence (OIE, 2010). The serotype 1 comprises all the virulent oncogenic strains and their derivatives, however, serotype 2 and serptype 3 , herpesvirus of turkeys (HVT) are mild and can be used as vaccinal strains (Islam and Walkden-Brown, 2007 and Malkinson et al., 1992). Serotype 1 is also classified into different pathotype strains, ranging from mild to very virulent plus strains (Witter, 1983 and Witter et al., 2005).

In Hungary, first description of Marek's disease was fitted as polyneuritis (Marek, 1907) in cockerels. In poultry flocks, inhalation of infected dust is the main route of infection with subsequent complex cycle of the virus, then shedding of virus from the feather follicle of infected birds serves as a source of contamination of the environment (Baigent and Davison, 2004). Chickens are the most important host for MD, but quail, turkeys, and pheasants are also susceptible to virus infection (Witter and Schat, 2003).

In Egypt, the first report of MD classical form was in 1954 (Soliman et al., 1954) and several reports including 
pathological, virological and/or seroepidemiological studies have been reported (Sheble et al., 1973). MD could be controlled by mono-valent or multivalent live virus vaccines of various types in ovo or at hatching (Witter, 1998).

The present study aimed to isolate MDV from diseased chickens flocks infected with MDV in Egypt using ECEs and identification of the virus using agar gel precipitation test (AGPT) and indirect fluorescence antibody test (IFAT) in both field tissues and in egg passaged samples after three passages - Molecular identification of MDV after collected field tissues by conventional and real-time (PCR).

\section{MATERIALS AND METHODS}

\subsection{Clinical specimens:}

A total of 16 pooled samples including feather follicle epithelium, ovary, kidney and spleen (4 samples for each organ) were collected from diseased chicken's flocks suspected to be infected with MDV. Each sample was pooled randomly from three to five birds (90 to 360 days old). Diseased chicken exhibited depression, paralysis of legs and wings, torticollis and grey eye. Samples of feather follicle epithelium, ovary, kidney and spleen from apparently healthy chickens ( 25 weeks old) were included as negative controls. Each collected sample was divided into two parts: part was taken rapidly to the freezing chamber of a cryostat for IFAT and another part was put in a sterile plastic bottle containing phosphate buffer saline (PBS) with antibiotics then transported to the laboratory in an ice box and stored at $20^{\circ} \mathrm{C}$ till used for virus isolation and identification.

\subsection{Standard MDV:}

FC-126 strain of Turkey Herpesvirus (HVT) (FaTRo veterinary pharmaceutical industry) was used. It was supplied in lyophilized vials; each vial contained 1000 doses and had a titer of $1500 \mathrm{PFU} / \mathrm{ml}$. The vaccine was prepared in fibroblasts tissue cultures. It was used for hyperimmune serum preparation and as a positive control in virus identification by AGPT and PCR.

\subsection{Preparation of the samples collected for virus isolation:}

Samples were prepared according to (Burleson, 1992) as follows: One gram of each sample was minced using sterile scissors and forceps then homogenized in a mortar containing sterile sand with a pestle. Phosphate buffered saline (PBS) containing antibiotics was added, making $20 \%(\mathrm{w} / \mathrm{v})$ suspension. The suspension was frozen and thawed three times and centrifuged at $3000 \mathrm{rpm}$ for 10 minutes. The supernatant was collected and stored at $-20^{\circ} \mathrm{C}$ till used.

\subsection{Inoculation of the prepared samples on CAM of ECEs:}

Inoculation of prepared samples on chorioallantoic membranes (CAMs) of 12 days old ECEs was carried out according to Burleson, (1992) and Biggs and Milne, (1971). The air space was created beneath the lateral walls of the egg by sucking the air through the blunt end of the egg with the help of teat. A volume of $0.2 \mathrm{ml}$ of prepared sample was inoculated through the hole created over the air space. The holes were sealed with the help of the molten wax then incubated for 7 days at $37^{\circ} \mathrm{C}$. Finally, the dead embryos at 3-5 days post inoculation and all living embryos at seven days were chilled for 6 hours then harvested aseptically and examined for MDV specific lesions and observed lesions were recorded. Three passages were carried out for each sample.

\subsection{Preparation of rabbit hyperimmune sera of standard MDV :}

It was done according to Mikami and Bankowski (1971) as follows: four NewZealand white rabbits were inoculated by four $\mathrm{s} / \mathrm{c}$ injection of $1 \mathrm{ml}$ of reconstituted vaccine emulsified with $1 \mathrm{ml}$ of Freunds complete adjuvant (first and third injection) and $1 \mathrm{ml}$ of reconstituted vaccine emulsified with 1 $\mathrm{ml}$ of Freunds incomplete adjuvant (second and fourth injection) at 2 week intervals. The rabbits bled out 14 days after the last injection and the hyperimmune serum was separated by centrifugation at 3000rpm for 10 minutes and kept at $-20^{\circ} \mathrm{C}$ till used. The fifth rabbit was not injected and housed separately from injected rabbits for collection of a negative control serum sample. The concentration of total proteins was detected by spectrophotometer and the reactivity of prepared hyperimmune serum was tested by AGPT against standard MDV and examined later for observation of precipitation lines which indicate the positive results.

\subsection{Identification of the isolated virus:}

\subsubsection{Agar gel precipitation test (AGPT):}

The detection of suspected MDV in field tissues and 3rd egg passaged samples using AGPT was done according to Mikami and Bankowski (1971) as follows: $10 \mathrm{ml}$ of 1.5\% agarose dissolved in PBS ( $\mathrm{pH}$ 7.2) was poured in petri dish. In each dish, 6 peripheral wells and one central well were performed. The hyperimmune serum was put into the central well, while the peripheral surrounding wells were filled with the supernatant fluid of field tissues samples and $3^{\text {rd }}$ egg passage samples (embryo together with the CAM), control positive MDV(standard vaccine) and control negative MDV(normal tissues and CAM). Dishes are incubated at $37^{\circ} \mathrm{C}$ in a humidified chamber for 5 days and examined later for observation of precipitation lines which indicate the positive results.

\subsubsection{Indirect fluorescence antibody test (IFAT) for detection of MDV in field samples and 3rd egg passages:}


It was carried out according to Naito et al., (1970) as follows:

Prepared cryostat slides were fixed with cold acetone for 10 minutes then incubated for 1 hour at $37^{\circ} \mathrm{C}$ with a few drops of 1:100 dilution of the prepared rabbit hyperimmune serum in a humidified chamber. The slides were washed with PBS pH 7.2 for 30 minutes 3 times (10 minutes each). Slides were incubated for 30 minutes at $37^{\circ} \mathrm{C}$ in dark humidified chamber with few drops of 1:200 dilution of antirabbit FITC conjugate (Sigma Aldrich Company). Then, the slides were thoroughly washed with PBS 3 times for 15 minutes (5 minutes each), then mounted with glycerol, covered with a cover slip and examined under a fluorescent microscope to show yellowish green color which indicate a positive result

\subsubsection{Conventional Polymerase Chain Reaction:}

Four sample [follicle epithelium (1), ovary (1), spleen(1), kidney(1)] were selected to confirm MDV diagnosis using PCR . Oligonucleotide primers were designed according to Kalyani et al., (2010) for amplification of ICP4 gene of MDV. Oligonucleotide primers used in the PCR reaction were synthesized by sigma chemical company, USA. The primers were received in lyophilized form and resuspended in Tris/EDTA (TE) buffer to reach a final concentration of $100 \mathrm{p}$ $\mathrm{mol} / \mu /$ designed to amplify a specific segment of $318 \mathrm{bp}$. The primers sequens for PCR amplification were as follows: forward primer, 5' - GGACGCCCACCACGATTACTACC - 3 and reverse primer, $5^{\prime}$ - ACTGCCTCACACAACCTCATCTCC-3'. The PCR was carried out using a commercial kit My Taq PCR kit for ICP4 gene. The reaction mixture contained $12.5 \mu \mathrm{M}$ Master Mix, $1.5 \mu \mathrm{M}$ for each primer, $7 \mu \mathrm{L}$ of extracted target DNA and $2.5 \mu \mathrm{L}$ of nuclease free water added to make a volume of 25 $\mu \mathrm{L}$. The thermal profile was as follows: initial denaturation at 95 ㅇ for 5 minutes followed by 30 cycles of PCR consisting of denaturation at 95 ㅇ $\mathrm{C}$ for 1 minute, annealing at $60.8 \stackrel{\circ}{\circ}$ for 1 minute, extension for $1 \mathrm{~min}$ at 72 으, followed by final elongation for 10 minutes at 72 o $\mathrm{C}$. Amplified product analysis was carried out as described previously Viljoen et al., (2005). Briefly $10 \mu \mathrm{l}$ of the PCR product was mixed with $1 \mu \mathrm{l} 10 \times$ gel loading buffer and loaded to the individual wells of a $1 \%$ agarose gel. In addition, $2 \mu \mathrm{l}$ of a $100 \mathrm{bp}$ DNA molecular weight marker was loaded with $2 \mu$ l loading buffer in a single outside well to be used as DNA ladder. The amplified DNA products were detected in comparison with DNA ladder using the U.V. transilluminator. The gel was photographed.

\subsubsection{Real time - PCR:}

Confirmative identification of MDV in the four selected samples was carried out via real-time PCR Baigent et al.,(2005). It was done using primers specific for ICP4 gene Kalyani et al., (2010). It was applied in a final volume of $20-\mu \mathrm{l}$ reaction mix $.1 \mu \mathrm{L}$ of $10 \mu \mathrm{M}$ forward and reverse primers and $5 \mu \mathrm{L}$ of extracted DNA. Non template control reaction was used as negative control reaction. The optimum thermal cycling parameters gene included initial denaturation at $95 \stackrel{\circ}{\circ}$ for 10 minutes followed by 35 cycles of PCR consisting of denaturation at $95 \circ \mathrm{o}$ for $30 \mathrm{~s}$, annealing at 60.8 o $\mathrm{C}$ for $30 \mathrm{~s}$, extension for $1 \mathrm{~min}$ at 72 ㅇ․

\section{RESULTS}

As illustrated in table (1), out of the 16 collected samples, the virus was successfully isolated on CAM of ECEs from 14 samples $(87.5 \%)$ including $4(100 \%)$ samples from feather follicle epithelium, ovary and kidney and 2(50\%) samples from spleen. In positive cases the embryos showed stunted growth (Fig. 1), mottled appearance, swollen greenish pale liver and pale appearance of the heart. The harvested CAM gave pock lesions. These lesions became more pronounced in the $2^{\text {nd }}$ passage and $3^{\text {rd }}$ passage.

Table (1): Comparative results of the virus isolation and identification in 16 prepared field samples and after 3rd passage using AGPT and IFAT:

\begin{tabular}{|c|c|c|c|c|c|c|c|c|c|c|c|}
\hline \multirow{3}{*}{$\begin{array}{l}\text { Samples } \\
\text { type }\end{array}$} & \multirow{3}{*}{$\begin{array}{c}\text { No. of } \\
\text { samples } \\
\text { collected }\end{array}$} & \multirow{2}{*}{\multicolumn{2}{|c|}{$\begin{array}{c}\text { Virus } \\
\text { isolation } \\
3^{\text {rd }} \\
\text { passage } \\
\text { positive } \\
\text { samples }\end{array}$}} & \multicolumn{4}{|c|}{ AGPT } & \multicolumn{4}{|c|}{ IFAT } \\
\hline & & & & \multicolumn{2}{|c|}{$\begin{array}{c}\text { Field } \\
\text { tissues } \\
\text { positive } \\
\text { samples }\end{array}$} & \multicolumn{2}{|c|}{$\begin{array}{c}3^{\text {rd }} \\
\text { passage } \\
\text { positive } \\
\text { samples }\end{array}$} & \multicolumn{2}{|c|}{$\begin{array}{c}\text { Field } \\
\text { tissues } \\
\text { positive } \\
\text { samples }\end{array}$} & \multicolumn{2}{|c|}{$\begin{array}{c}3^{\text {rd }} \text { passage } \\
\text { positive } \\
\text { samples }\end{array}$} \\
\hline & & No. & $\%$ & No. & $\%$ & No. & $\%$ & No. & $\%$ & No. & $\%$ \\
\hline \multicolumn{12}{|l|}{ Feather } \\
\hline Follicle & 4 & 4 & 100 & 3 & 75 & 2 & 50 & 4 & 100 & 4 & 100 \\
\hline \multicolumn{12}{|l|}{ Epithelium } \\
\hline Ovary & 4 & 4 & 100 & 2 & 50 & 2 & 50 & 2 & 50 & 3 & 75 \\
\hline Spleen & 4 & 2 & 50 & 1 & 25 & 1 & 25 & 2 & 50 & 3 & 75 \\
\hline Kidney & 4 & 4 & 100 & 2 & 50 & 1 & 25 & 2 & 50 & 3 & 75 \\
\hline Total & 16 & 14 & 87.5 & 8 & 50 & 6 & 37.5 & 10 & 62.5 & 13 & 81.25 \\
\hline
\end{tabular}

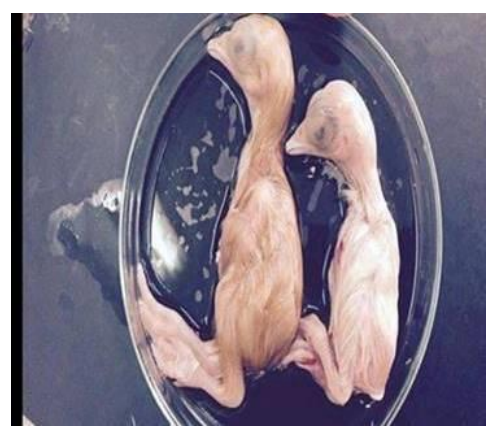

Figure 1- Egg embryo inoculated with prepared sample after 2nd passage showing stunted growth comparing with normal embryo.

White line of precipitation was observed within five days between prepared hyperimmune serum and 8 (50\%) field samples including 3 (75\%) samples from feather follicle epithelium (Fig. 2), 2 (50\%) samples from ovary and kidney and $1(25 \%)$ sample from spleen. 
Table 2. Identification of the virus nucleic acid in four selected samples from feather follicle epithelium, ovary, spleen and kidney by PCRand gel electrophoresis

$\begin{array}{cccc}\text { O. } & \text { Farm NO. } & \text { Type of sample } & \text { PCR reaction } \\ \text { O. } & 1 & \text { Feather follicle epithelium } & + \\ : & 1 & \text { Ovary } & + \\ \vdots & 4 & \text { Spleen } & + \\ < & 4 & \text { Kidney } & +\end{array}$

Also, white line of precipitation was observed within five days between prepared hyperimmune serum and 6 (37.5\%) egg passage samples after $3^{\text {rd }}$ passage in ECEs including $2(50 \%)$ from feather follicle epithelium and ovary and one sample spleen.

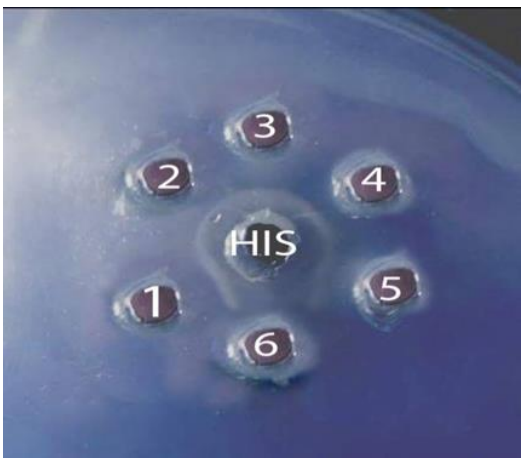

Figure2 - Result of AGPT for MDV identified in feather follicle epithelium sample: Well (1:4): Feather follicle epithelium sample collected from diseased chickens. Well (5): MDV control +ve. Well (6): Negative control sample. HIS Well: Hyper immune serum.

Regarding IFAT, yellowish green color as positive result appeared in 10 (62.5\%) field samples including 2 samples (50\%) from ovary, spleen and kidney and 4 samples (100\%) from feather follicle epithelium samples (Fig. 3-4). The positive results showed in frozen CAMs prepared sections (after $3^{\text {rd }}$ passage) were $13(81.25 \%)$ including 4 samples (100\%) from feather follicle epithelium and 3 samples (75\%) from ovary, spleen and kidney samples. None of the negative control samples showed any positive reaction.

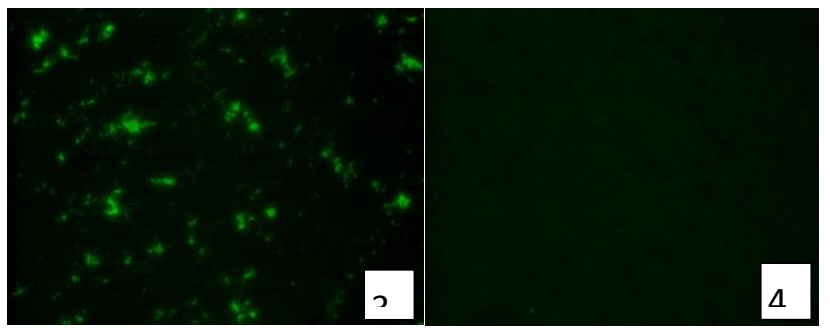

Figure $\mathbf{3}$ - Positive immunofluorescence reaction showing yellowish green color in feather follicle epithelium section X40.

Figure 4 - Negative control immunofluorescence reaction, no yellowish green color in feather follicle epithelium cryostat section $\mathrm{X} 40$
The results in table (2) showed that results of application of PCR for amplification of ICP4 gene of the virus in field collected samples followed by gel electrophoresis showed that all tested samples revealed the positive results of ICP4 gene amplification with correct size (318 bp ) (Fig.5) Four samples were selected for confirmation of MDV diagnosis in chickens by real time - PCR was carried out. Four field samples from feather follicle epithelium, ovary, spleen and kidney (one of each organ) . These samples gave threshold cycles (Ct) from 28.57 to 31.6. While non-template control (NTC) gave negative results.

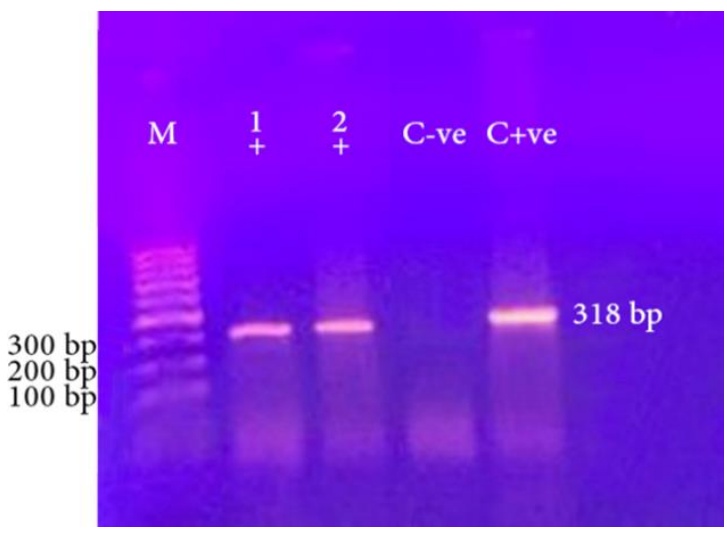

Figure 5 - Agarose gel electrophoresis of PCR products for ICP4 gene (318 bp) of MDV in field tissues. M : DNA marker. Lane 1: The amplified product prepared from collected ovary sample. Lane 2: The amplified products prepared from collected feather follicle epithelium sample. $\mathbf{C}+\mathbf{v e}$ : The amplified products prepared from standard MDV. C -ve: The PCR products prepared obtained from negative control sample.

\section{DISCUSSION}

In this study, trials for isolation, identification and molecular detection of MDV from the 16 different poultry farms at Dakahlia Governorate, Egypt were carried out.

Diseased chickens showed clinical signs of depression, paralysis of legs and wings, torticollis, ataxia and grey eye. This is in agreement with, Ekperigin et al., (1983) and Schat and Nair,) 2008) who showed same clinical signs of MDV infected chickens.

The present study concerned with trials for isolation of MDV from feather follicle epithelim, ovary, spleen and kidney samples from infected chickens on fertile chicken eggs with further identification by means of conventional serological tests as AGPT and IFAT in addition to molecular detection of the virus using conventional and real time PCR.

MDV was isolated from samples collected from naturally infected chicken by inoculation on CAMs of ECE. Characteristic pock lesions were observed after $1^{\text {th }}$ passage and become clear at $2^{\text {nd }}$ and $3^{\text {rd }}$ passage. In positive cases, the embryos showed stunted growth, mottled appearance and ecchymotic haemorrhages and swollen greenish pale liver as well as pale 
appearance of the heart .These signs became more pronounced from the $2^{\text {nd }}$ passage. This finding come in partial agreement with Evans etal., (1971) who detected pock lesion in ECE inoculated with MDV.

Isolated MDV was identified by AGPT and IFAT. Clear precipitation lines were appeared by AGPT using refrence MDV antisera in $8(50 \%)$ field samples and $6(37.5 \%) 3^{\text {rd }}$ passage egg samples. This result in harmony with Adldinger and Calnek (1973) who used AGPT in detection MDV antigens. Charactristic specific yellowish green fluorescent color were appeared in IFAT in 10 (62.5\%) field samples and 13 (81.25\%) $3^{\text {rd }}$ passage egg samples observed by Lee et al., (1983) who used immunofluorescence test for MDV diagnosis.

AGPT is superior in virus detection in field samples over CAMs samples due to high concentration MDV antigen in field samples than in CAMs of ECEs. Detection of MDV by AGPT as well as appearance pock lesions on CAM of ECEs indicates in that our identified MDVs from vaccinated farms are virulent strains as previously reported by Maas et al., (1978).

IFAT is superior over AGPT in virus detection in field samples and in egg passage samples ( $3^{\text {rd }}$ passage) in ECE as AGPT need high concentration of antigen to be detected Grewal and singh , (1976).

The conventional PCR assay used in this work showed high sensitivity as aunique band of expected size $318 \mathrm{bp}$ was obtained from all selected samples derived from (feather follicle epithelium, ovary, spleen, kidney). This finding of molecular identification of virus is in accordance with Kalyani et al., (2010) who confirmed MDV infection in Ethiopia by applied PCR using primers were designed to amplify specific segment ICP4 gene. Also all selected samples gave positive results by real-time PCR . Real-time PCR assay gave threshold cycles (Ct) from 28.57 to 31.6. While non-template control (NTC) gave negative results.

Real-time PCR for confirmation of MDV diagnosis is preferable over conventional as it doesn't need gel electrophoresis after PCR amplification, more rapid and not much more expensive than conventional PCR except the equipment cost (Wiedbrauk and Farkas, 1995).

The results obtained showed that the virus detected in feather follicle epithelium and different internal organs (ovary, spleen, kidney) of naturally infected chickens. These indicated that MDV replicated in both feather follicle epithelium and internal organs. This finding is in harmony with Schat and Nair, (2008) who stated that the source of infectious cell-free virus is the feather follicle epithelium, which is the only site where fully productive infection and release of cell-free MDV occurs. That dissemination of MDV from the primary lesion site of replication to the draining lymphnode and then to the systemic circulation with location to other tissues including (ovary, spleen, and kidney) has occurred.

\section{Conclusion}

MDV in both field and egg passaged samples ( $3^{\text {rd }}$ passage) was identified by AGPT and IFAT and molecular detected by conventional and real-time PCR.Virus detection by AGPT and IFAT in field samples is superior over virus detection in egg passage samples. Identified MDV from vaccinated farms is virulent strain. IFAT is superior over AGPT in virus detection.

\section{Conflict of interest}

Authors declare that they have no conflict of interest

\section{REFERENCES}

Adldinger, H. K. and Calnek, B. W. (1973): Pathogenesis of Marek's disease: early distribution of virus and viral antigens in infected chickens. Journal of the National Cancer Institute. 50:1287-1298.

Baigent, S.J. and Davison, F. (2004): Marek's disease virus: biology and life cycle. In: Marek's disease: An Evolving Problem, Davison F. \& Nair V., eds. Elsevier Academic Press. London. UK 62-77.

Baigent,S.J.,Petherbridge,L.J., Howes,K., Smith,L.P., Currie,R.J., Nair,V.K. (2005): Absolute quantitation of Marek's disease virus genome copy number in chicken feather and lymphocyte samples using real-time PCR Journal of Virology. Methods.23 . pp. 53-64

Biggs, P. M. and Milne. B.S. (1971): Use of the embryonating egg in studies on Marek's disease. American Journal of Veterinary Research 32:1795-1809.

Burleson, F. G., Chambers, T. M. and Wiedbrauk, D. L. (1992): Virology, a laboratory manual. 1st ed. Academic press I, VC.

Davison, A. J. (2010): Herpesvirus systematics. Veterinary. Microbiology. 16: 143(1):52-69.

Ekperigin, H. E., Fadly, A. M., Lee, L. F., Liu, X. and McCapes, R. H. (1983): "Comb Lesions and Mortality Patterns in White Leghorn Layers Affected by Marek's Disease". Avian Disease. 27: 503512

Evans, D. L., Patterson L.T. and Beasley,J.N. (1971): Pathological response of chicken embryo to an agent which causes acute leukosis (Marek's disease). Applied. Microbiology. 21:321-326.

Grewal, G. S. and Singh, B. (1976): "Incidence of Marek's Disease Virus Infection in Domestic Fowl of Punjab (India)". Avian Disease. 20:191-194.

Islam, A., Walkden-Brown, S.W. (2007): Quantitative profiling of the shedding rate of the three Marek's disease virus (MDV) serotypes reveals that challenge with virulent MDV markedly increases shedding of vaccinal viruses. Journal of general virology. 88(8):2121-2128.

Kalyani, I.H., Tajpara, M.M., Jhala, M.K., Bhanderi, B.B., Nayak, J.B. and Purohit, J.H., (2010): Characterization of the ICP4 gene in pathogenic Marek's disease virus of poultry in Gujarat, India, using PCR and sequencing, Veterinarski Arhiv Journal. 80. 683-692.

Lee, L. F., Liu, X. and Witter, R. L. (1983 ): "Monoclonal antibodies with specificity for three different serotypes of Marek's disease viruses in chickens". Journal Immunology. 130:1003-1006.

Maas, H. 1. L., van Vloten, J., Vreede-Groenewegen, A E. and Orthel, F. W (1978): Control of Marek's disease in the Netherlands: Large scale field trials with the avirulent cellassociated Marek's disease vaccine virus (strain CVI988). Avian Pathology. 7,79-86

Malkinson M., Davidson I., Becker, Y. (1992) : Antigen B of the vaccine strains of Marek's disease virus and herpesvirus of turkeys presents heat-labile group and serotype specific epitopes. Archis of virology. 127(1-4):169184

Marek, J. (1907): Multiple Nervenentzuendung (Polyneuritis) bei Huehnern Deutsche Tierärztliche Wochenschrift 15:417-421.

McKay, J. C. (1998): A poultry breeder's approach to avian neoplasia. Avian Pathology. 27: S74 - S77. 
Mikami,T., Bankowski , R .A(1971) :Payhogenetic and serologic studies on type 1 and type 2 plaque -producing agents derived from Cal-1 strain of Marek's disease virus.Amer journal of veterinary research .32,303-317.

Naito, M., Ono, K., Tanabe, S., Doi, T ., Kato , S. (1970): Detection in chicken and human sera of antibody against herpes type virus from achicken with Marek's disease and EB virus demonstrated bu the indirect immunofluorescence test . BiKen Journal . 13,205-212.

OIE. (2010): Office International des Epizootics, chapter 2.3.13: Marek's disease, Manual of diagnostic test and vaccines for terrestrial animals, France. Pp: 1-11.

Schat, K. A. and Nair, V. (2008): Marek's disease". In: Y. M. Saif, A. Fadly, J. R. Glisson, L. R. McDougald, L. K. Nolan and D. E. Swayne (Eds) Diseases of poultry, 12th Ed. PP. 452-514. Blackwell Publishing Professional State Avenue, Ames, lowa.

Sheble, A.; Barhouma, N., Saber, M.S., El-Assily, S., El-Sabbagh, A., Ibrahim, S.N., Allam, M.S., Sabban, M.S., Nafie, E., Almassy, K. and Ahmed, A.A.S. (1973): "Preliminary investigations on Marek's disease in Egypt". Abstracts 11th Arab Veterinary. Cong., Cairo, 17-23 March, P. 41.

Soliman,K. N.; El- Agroudi, M.A.;Nadim, S.; and Abdilhalim, M.I. (1954): The Occurrence of the neural type of the avian leukosis complex in Egypt. British. Veterinary. Journal. 110: 271-277

Viljoen G.J., Nel L.H. and Crowther J.R.(2005): Molecular diagnostic PCR hand book. IAEA

Wiedbrauk, D . L. and Farkas, D. H. (1995) : Molecular methods for virus detection. Academic Press.

Witter, R. L. (1983): Characteristics of Marek's disease viruses isolated from vaccinated commercial chicken flocks: association of viral pathotype with lymphoma frequency. Avian Disease. 27:113-132.

Witter, R. L. (1998): The changing landscape of Marek's disease. Avian Pathology. 27:S46-S53.

Witter, R. L. and Schat, K. A. (2003) : Marek's disease. In: Y. M. Saif, H. J. Barnes, A. M. Fadly, J. R. Glisson, L. R. McDougald, and D. E. Swayne (Eds.). Diseases of poultry, 11th Ed. PP. 407-465. Iowa State University Press, Ames, lowa

Witter, R. L., Calnek . B. W., Buscaglia.C., Gimeno .I.M., and Schat.K. A (2005): Classification of Marek's disease viruses according to pathotype: philosophy and methodology. Avian Pathology 34:75-90. 